www.nature.com/pj

\title{
Physical, optical and gas transport properties of new processable polyimides and poly(amideimide)s obtained from 4,4'-[oxybis(4,1-phenylenethio)]dianiline and aromatic dianhydrides
}

\author{
Eugenia Grabiec $^{1}$, Ewa Schab-Balcerzak ${ }^{1,2}$, Aleksandra Wolińska-Grabczyk ${ }^{1}$, Andrzej Jankowski ${ }^{1}$, \\ Bożena Jarząbek ${ }^{1}$, Justyna Kożuch-Krawczyk ${ }^{3}$ and Małgorzata Kurcok ${ }^{3}$
}

Aromatic diamine 4,4'-[oxybis(4,1-phenylenethio)]dianiline and various dianhydrides with isopropylidene, hexafluoroisopropylidene, fluorenylidene diphenyl, ether, thioether and/or amide linkages were applied in a polycondensation reaction to obtain new processable polyimides and poly(amideimide)s (PIs). PIs were synthesized by the conventional two-step procedure of ring-opening polyaddition and subsequent thermal cyclic dehydration. The structures of the polymers were characterized with Fourier-transform infrared spectroscopy and elemental analysis. The thermal behaviors of the PIs were characterized with differential scanning calorimetry, thermogravimetric analysis and dynamic mechanical thermal analysis. The glass transition temperature $\left(T_{\mathrm{g}}\right)$ of the PIs were in the range of $175-298{ }^{\circ} \mathrm{C}$ and depended on the dianhydride used. The $5 \%$ weight loss temperatures were in the range of $423-515{ }^{\circ} \mathrm{C}$, which shows the high thermal resistance characteristics of the PI. The optical absorption properties in the UV-visible range of the obtained polymers were studied in solution and in the solid state. The average refractive indices ( $n$ ) of the PI films measured at the low absorption range were in the range of 1.96-1.50. The permeation properties of the Pls were studied for $\mathrm{He}, \mathrm{O}_{2}, \mathrm{~N}_{2}$ and $\mathrm{CO}_{2}$ at $6 \mathrm{~atm}$, with a constant pressure/variable volume setup. The hexafluoroisopropylidene-based PI showed the largest permeability for all gases.

Polymer Journal (2011) 43, 621-629; doi:10.1038/pj.2011.28; published online 20 April 2011

Keywords: gas transport properties; optical properties; polyimides; sulfur-containing polyimides

\section{INTRODUCTION}

Aromatic PIs belong to one of the most important classes of high-performance polymers because of their outstanding physical and chemical properties. Their thermal and chemical stability, high glass transition temperature $\left(T_{\mathrm{g}}\right)$, mechanical strength, low dielectric constant, low coefficient of thermal expansion, high radiation resistance, optical transparency, high temperature alignment stability and low optical loss have secured a permanent place for them in a variety of applications. ${ }^{1-3}$ PIs have been the subject of intense research for many years, both from the basic research and from application standpoints. Some common applications of PIs include dielectric films for the electronic industry, orientation layers in the liquid crystal industry, lightweight load-bearing heatresistant composites and adhesives for the aerospace industry and gas-separation membranes for modern technologies. The growth of modern technology has posed a constantly increasing need for materials that can perform well under harsh conditions, such as elevated temperatures, ${ }^{4}$ and processable PIs with special properties have become a subject of great interest all over the world. ${ }^{5,6}$ It was found that compounds containing imine rings have prospective applications in organic (opto)electronics and related fields, and that they are exemplary as materials for fabricating field-effect transistors, ${ }^{6-8}$ organic light-emitting diodes, ${ }^{9-12}$ solar cells ${ }^{12-14}$ and photonic devices. ${ }^{15-17}$ With regard to the PI microstructure, much effort is being devoted to the design and synthesis of PIs with thioether linkages. ${ }^{18-26}$ One of the most popular research directions in sulfur-containing PI is the investigation of their use as high refractive index $(n)$ materials. ${ }^{27-28}$ High $n$ polymers have been widely proposed for applications in advanced optoelectronic fabrication, such as high-performance components for advanced display devices, encapsulates for organic light-emitting diode devices, microlens component for charge-coupled devices, complementary metal oxide semiconductor image sensors, ${ }^{20,21,25,28,29}$ antireflective coatings and for telecommunication systems as optical waveguide

\footnotetext{
${ }^{1}$ Centre of Polymer and Carbon Materials, Polish Academy of Sciences, Zabrze, Poland; ${ }^{2}$ Faculty of Mathematics, Physics and Chemistry, Institute of Chemistry, University of Silesia, Katowice, Poland and ${ }^{3}$ Paint and Plastic Department, Institute for Engineering of Polymer Materials and Dyes, Gliwice, Poland

Correspondence: Professor E Schab-Balcerzak or Professor A Wolińska-Grabczyk, Centre of Polymer and Carbon Materials, Polish Academy of Sciences, 34, M. CurieSklodowska Street, Zabrze, Poland.

E-mail: eschab-balcerzak@cmpw-pan.edu.pl, ewa.schab-balcerzak@us.edu.pl or aleksandra.wolinska@cmpw-pan.edu.pl

Received 15 October 2010; revised 27 January 2011; accepted 11 March 2011; published online 20 April 2011
} 
devices. ${ }^{23}$ Moreover, such PIs are interesting for their potential applications as memory devices, ${ }^{30}$ membranes for gas separation ${ }^{18,19,31}$ and membranes for fuel cells. ${ }^{32}$

Various sulfur-containing PIs have been recently developed. These polymers mainly consisted of diamine with thioether linkages in skeletal structures, such as $4,4^{\prime}$-diaminodiphenyl sulfide, ${ }^{33}$ oligo(phenylene thioether) diamines, ${ }^{18,19} 4,4^{\prime}$-thiobis[( $p$-phenylenesulfanyl)aniline], ${ }^{20,21}$ 2,7-bis(4-aminophenylenesulfanyl)thianthrene, ${ }^{21,22}$ 2,2'-bis-(trifluoromethyl)-4,4'-diaminodiphenyl sulfide, ${ }^{23}$ 1,6-bis ( $p$-aminophenylsulfanyl)-3,4,8,9-tetrahydro-2,5,7,10-tetrathiaantracene, ${ }^{24}$ 2,5-bis(4-aminophenylsulfanyl) tiophene, 2,5-bis $\left\{2^{\prime}\right.$ - [5'-(4' -aminophenyl) sulfanyl]thienyl tiophene, ${ }^{25}$ 2,6-bis[4-(4-aminophenylsulfanyl) phenyl]-2-phenylpyridine, $4,4^{\prime}$-( $p$-phenylenedisulfanyl)dianiline, $4,4^{\prime}$-bis ( $p$-aminophenylsulfanyl) biphenyl, 2,7-bis(4-aminophenylenesulfanyl) thianthrene and $4,4^{\prime}$-sulfonylbis[( $p$-phenylenesulfanyl)aniline $] .{ }^{26}$

In this paper, we report the synthesis of new PIs containing thioether linkages originating from 4,4'-[oxybis(4,1-phenylenethio)]dianiline. This diamine was used for condensation with various dianhydrides containing isopropylidene, hexafluoroisopropylidene, fluorenylidene diphenyl, ether, thioether and/or amide linkages. The purpose of this work was to study the optical and gas transport properties of this new group of polymers along with their physical properties and structures to find relationships among their physical structure and observed properties.

\section{EXPERIMENTAL PROCEDURE}

\section{Materials}

4,4'-(1,3-Phenylenedioxy)dianiline, $N$-methyl-2-pyrrolidinone (NMP), trimellitic anhydride acid chloride and other necessary starting chemicals were purchased from Aldrich Chemical (St Louis, MO, USA) and were used as received. 4,4'-(9-Fluorenylidene)dianiline was recrystallized from methanol in the presence of decolorizing charcoal. 4,4'-[Oxybis(4,1-phenylenethio)] dianiline (m.p. $116^{\circ} \mathrm{C}$ ) was a gift. Two dianhydrides were used for the PI preparation, namely, 4,4'-(4,4'-isopropylidene-diphenoxy)bis(phthalic anhydride) and (4,4'-(hexafluoroisopropylidene)diphthalic anhydride), which were purchased from Aldrich Chemical.

Two other dianhydrides, namely, $1,1^{\prime}$-bis $\left(3^{\prime \prime}, 4^{\prime \prime}\right.$-dicarboxybenzoiloamino) 1,3-phenylenedioxy) dianhydride and $1,1^{\prime}$-bis $\left(3^{\prime \prime}, 4^{\prime \prime}\right.$-dicarboxybenzoiloamino)$9,9^{\prime}$-diphenylofluorene dianhydride, which were applied for the synthesis of the poly(amideimide)s, were synthesized according to the method described in our previous works for similar compounds. ${ }^{34-36}$ Helium, oxygen, nitrogen and carbon dioxide with a purity of $99.9 \%$ were purchased from Air Products Sp. z o.o., Warsaw, Poland, and they were used as received.

\section{Measurements}

Infrared spectra were acquired on an FTS $40 \mathrm{~A}$ Fourier-transform infrared (FTIR) spectrometer (Bio-Rad, Digilab Division, Cambridge, MA, USA) between 4000 and $400 \mathrm{~cm}^{-1}$ at a resolution of $2 \mathrm{~cm}^{-1}$ and for an accumulated 32 scans. Samples were analyzed as $\mathrm{KBr}$-pressed pellets or films. Elemental analysis was performed with a Vario EL III apparatus (Elementar, Hanau, Germany). UV-visible (UV-Vis) spectra were recorded at room temperature using a two-beam V-570 UV-Vis-NIR spectrophotometer (Jasco, Tokyo, Japan). Absorption spectra of polymer solutions in tetrahydrofuran (THF) and NMP were recorded using the quartz cells within a wavelength interval of up to $500 \mathrm{~nm}$, depending on the transparency of the solvent. Transmission $(T \%)$ and reflectivity $(R \%)$ measurements for thin films of polymers were recorded for the whole spectral range of the spectrophotometer, that is, 200-2500 nm (except transmission for the films on glass substrates). During the reflectivity measurements, a special two-beam reflectance arrangement was used with an $\mathrm{Al}$ mirror in the reference beam as a reflectance standard. X-ray diffraction patterns of solid samples, powders and films were recorded using $\mathrm{Cu}$ $\mathrm{K} \alpha$ radiation (wavelength $\lambda=1.54051 \AA$ ) on a wide-angle HZG-4 diffractometer (Carl Zeiss, Jena, Germany) in the typical Bragg geometry. The X-ray diffraction angle $\Theta$, at which the maximum of a broad peak appeared on the wideangle X-ray diffraction (WAXD) profile, and the following Bragg's expression,

$$
\lambda=2 d \times \sin \Theta
$$

were used to calculate the average interchain distance known as $d$-spacing. Differential scanning calorimetry (DSC) was performed with a TA-DSC 2010 apparatus (TA Instruments, Newcastle, DE, USA) under nitrogen, using a heating/cooling rate of $20^{\circ} \mathrm{C}$ per min. The $T_{\mathrm{g}}$ was taken to be the midpoint of the heat capacity step change observed in the second run. Thermogravimetric analysis (TGA) was performed with a TGA/SDTA $851^{\mathrm{e}}$ apparatus (MettlerToledo International, Greifensee, Switzerland) with a heating rate of $10^{\circ} \mathrm{C}$ per min under a nitrogen atmosphere. Dynamic mechanical thermal analysis (DMA) was performed from 0 to $210^{\circ} \mathrm{C}$ in the bending mode at $1 \mathrm{~Hz}$, at a heating rate of $3{ }^{\circ} \mathrm{C}$ per min, a force of $14 \mathrm{~N}$ and an amplitude of $1 \mu \mathrm{m}$. The molar masses and polydispersities $\left(M_{\mathrm{w}} / M_{\mathrm{n}}\right)$ of the polymers were determined by gel permeation chromatography measurements recorded in dimethylformamide as an eluent at $80^{\circ} \mathrm{C}$ with a flow rate of $1 \mathrm{ml} \mathrm{min}^{-1}$ using a polystyrene standard. A Knauer apparatus with MIXED-DPL gel columns (Knauer, Bad Hamburg, Germany) was used. The density of the polymer membranes was determined by a buoyancy method by weighing the samples in water and in air. The membrane density was calculated as follows:

$$
\rho=\frac{m_{\mathrm{A}}}{m_{\mathrm{A}}-m_{\mathrm{L}}} \rho_{0}
$$

where $m_{\mathrm{A}}$ is the membrane weight in air, $m_{\mathrm{L}}$ is the membrane weight in water and $\rho_{0}$ is the density of water. The pure gas permeability in the polymers was determined with a constant pressure/variable volume method. The flow of the gas was measured using a soap bubble flowmeter $(0-0.1 \mathrm{ml})$. The feed side pressure of the gases was set at $6 \mathrm{~atm}$. The permeate side was maintained at atmospheric pressure. Before each measurement, the feed and permeate sides of the apparatus were evacuated and subsequently filled with a gas that was tested several times. The gas permeability was determined from the following equation:

$$
P=\frac{q \cdot l}{\left(p_{1}-p_{2}\right) \cdot A \cdot t}
$$

where $P$ is the gas permeability expressed in Barrer units $\left(1\right.$ Barrer $=10^{-10} \mathrm{~cm}^{3}$ (STP) $\mathrm{cm}$ per $\mathrm{cm}^{2} \mathrm{~s} \mathrm{~cm} \mathrm{Hg}$ ), $q$ is the quantity of permeant passing through the membrane $\left(\mathrm{cm}^{3}(\mathrm{STP})\right)$ in time $t(\mathrm{~s}), l$ is the membrane thickness $(\mathrm{cm}), p_{1}$ and $p_{2}$ are the pressures at both sides of the membrane and $A$ is the effective membrane area $\left(\mathrm{cm}^{2}\right)$. The experimental error in the permeability coefficients has been estimated to be $10-16 \%$, the error being larger the lower the gas permeability. The commercial PI film Ultem (Sabic Innovative Plastics, Pittsfield, MA, USA) was used as a standard. Gas permeabilities were measured in the sequence $\mathrm{He}, \mathrm{N}_{2}, \mathrm{O}_{2}$ and $\mathrm{CO}_{2}$.

The ideal selectivity was calculated from a single gas permeation experiment as:

$$
\alpha_{(\mathrm{A} / \mathrm{B})}=\frac{P_{\mathrm{A}}}{P_{\mathrm{B}}}
$$

\section{Synthesis of dianhydrides}

A mixture of $22 \mathrm{mmol}$ of trimellitic anhydride acid chloride and $25 \mathrm{ml}$ of dry acetone was added to a $100-\mathrm{ml}$ flask equipped with a magnetic stirrer, condenser and dropping funnel. After the mixture was heated under reflux, a solution of 10-mmol diamine and $22 \mathrm{mmol}$ of dry pyridine in $25 \mathrm{ml}$ of acetone was added dropwise. The mixture was stirred and heated under reflux for $2.5 \mathrm{~h}$. After cooling to room temperature, the resulting yellow precipitate was filtered off, washed with acetone and then dried at $60^{\circ} \mathrm{C}$. The crude product was washed with hot acetic anhydride and dried in vacuum at $200^{\circ} \mathrm{C}$. In this way, dianhydride was obtained as a yellow solid.

$1,1^{\prime}$-Bis $\left(3^{\prime \prime}, 4^{\prime \prime}\right.$-dicarboxybenzoiloamino) 1,3-phenylenedioxy dianhydride: yield: $80 \%$; melting temperature is in the range of $309-313^{\circ} \mathrm{C}$; $\mathrm{IR}\left(\mathrm{KBr}, \mathrm{cm}^{-1}\right): 1849$, $1773,1722(\mathrm{C}=\mathrm{O}$ in anhydride), $1674(\mathrm{C}=\mathrm{O}$ in amide). Elemental anal calcd for $\mathrm{C}_{36} \mathrm{H}_{20} \mathrm{~N}_{2} \mathrm{O}_{10}$ : C, $67.50 \%$; H, 3.15\%; and N, 4.37\%; found: $\mathrm{C}, 67.38 \% ; \mathrm{H}$, $3.18 \%$; and $\mathrm{N}, 4.38 \%$.

$1,1^{\prime}$-Bis $\left(3^{\prime \prime}, 4^{\prime \prime}\right.$-dicarboxybenzoiloamino)-9,9'-diphenylofluorene dianhydride: yield: $70 \%$; the range of melting temperature is $387-393^{\circ} \mathrm{C}$; IR $\left(\mathrm{KBr}, \mathrm{cm}^{-1}\right)$ : 
$1855,1775,1718$ ( $\mathrm{C}=\mathrm{O}$ in anhydride), 1663 ( $\mathrm{C}=\mathrm{O}$ in amide). Elemental anal calcd for $\mathrm{C}_{41} \mathrm{H}_{24} \mathrm{~N}_{2} \mathrm{O}_{8}$ : C, $73.21 \%$; $\mathrm{H}, 3.60 \%$; and $\mathrm{N}, 4.17 \%$; found: $\mathrm{C}, 72.96 \%$; $\mathrm{H}, 3.39 \%$; and N, $4.09 \%$.

\section{Synthesis of polymers (PIs)}

The polymers were prepared with polycondensation reactions of equimolar amounts of 4,4'-[oxybis(4,1-phenylenethio)]dianiline, with various dianhydrides in NMP as a solvent (20\% of the total monomer concentration). The reaction was performed in two steps. In the first step, the reaction mixture was stirred for $20 \mathrm{~h}$ at room temperature under an argon atmosphere to prepare viscous poly(amic acid). Thereafter, the poly(amic acid) was thermally cyclized at $175^{\circ} \mathrm{C}$ for $8 \mathrm{~h}$. After this step, the resultant solution of the polymer was cooled to room temperature and precipitated in methanol. The precipitate was collected by filtration and washed with hot methanol to remove any residual solvent. The resulting polymer was dried at $70{ }^{\circ} \mathrm{C}$ under vacuum for at least $24 \mathrm{~h}$.

PI-I: FTIR $\left(\mathrm{KBr}, \mathrm{cm}^{-1}\right): 1778,1720(\mathrm{C}=\mathrm{O}$ in imide), 1659,1590 (in the polymer backbone amide I and amide II), 1369, 722 (C-N stretching), 1081 (Ar-S-Ar), 1237, 1219 (C-O-C). Anal calcd for $\left(\mathrm{C}_{60} \mathrm{H}_{36} \mathrm{~N}_{4} \mathrm{O}_{9} \mathrm{~S}_{2}\right)_{n}(1021.06)_{n}$ : C, 70.58; H, 3.55; and N, 5.48; found: $\mathrm{C}, 69.27 ; \mathrm{H}, 3.75$; and N, 5.42 .

PI-II: FTIR $\left(\mathrm{KBr}, \mathrm{cm}^{-1}\right)$ : 1778, $1722(\mathrm{C}=\mathrm{O}$ in imide), 1667, 1597 (in the polymer backbone amide I and amide II), 1371, 723 (C-N stretching), 1080 (Ar-S-Ar), 1237 (C-O-C). Anal calcd for $\left(\mathrm{C}_{67} \mathrm{H}_{40} \mathrm{~N}_{4} \mathrm{O}_{7} \mathrm{~S}_{2}\right)_{n}$ (1077.19) $)_{n}$ : C, 74.70; H, 3.74; and N, 5.20; found: C, 71.07; H, 4.18; and N, 5.81 .

PI-III: FTIR ( $\left.\mathrm{KBr}, \mathrm{cm}^{-1}\right): 1776,1722(\mathrm{C}=\mathrm{O}$ in imide), 1373, $745(\mathrm{C}-\mathrm{N}$ stretching), 1082 (Ar-S-Ar), 1239 (C-O-C). Anal calcd for $\left(\mathrm{C}_{55} \mathrm{H}_{36} \mathrm{~N}_{2} \mathrm{O}_{7} \mathrm{~S}_{2}\right)_{n}$ (901.00) ${ }_{n}$ : C, 73.32; H, 4.03; and N, 3.11; found: $\mathrm{C}, 71.07 ; \mathrm{H}, 4.15$; and N, 3.47.

PI-IV: FTIR $\left(\mathrm{KBr}, \mathrm{cm}^{-1}\right): 1783,1723(\mathrm{C}=\mathrm{O}$ in imide $), 1372,721(\mathrm{C}-\mathrm{N}$ stretching), 1083 (Ar-S-Ar), 1241 (C-O-C) 1210 (C-F). Anal calcd for $\left(\mathrm{C}_{43} \mathrm{H}_{22} \mathrm{~N}_{2} \mathrm{O}_{5} \mathrm{~S}_{2} \mathrm{~F}_{6}\right)_{n}(824.75)_{n}: \mathrm{C}, 62.62 ; \mathrm{H}, 2.69$; and $\mathrm{N}, 3.40$; found: $\mathrm{C}$, 61.32; H, 2.88; and N, 3.46

\section{Film preparation}

The polymer solutions ( $0.05 \mathrm{~g}$ in $2 \mathrm{ml} \mathrm{NMP}$ ) were filtered through a $0.5-\mu \mathrm{m}$ filter and then poured onto a glass plate and heated gradually from room temperature to $100^{\circ} \mathrm{C}$ over $3 \mathrm{~h}$. The resulting films were stripped off the glass substrates (except the PI-I film), and the free-standing films were dried in a vacuum oven at $110-160^{\circ} \mathrm{C}$ for $3 \mathrm{~h}$. The resultant films with the thicknesses in the range of $11-26 \mu \mathrm{m}$ were used for the UV-Vis measurements.

Membranes for gas permeability and $T_{\mathrm{g}}$ measurements (DMA, DSC) were prepared from a polymer solution ( $0.3 \mathrm{~g}$ of PI in $4 \mathrm{ml}$ of NMP), filtered through a $0.5-\mu \mathrm{m}$ filter and cast onto a Teflon plate mounted in a metal mold. The membranes were soft dried at $50-70{ }^{\circ} \mathrm{C}$ for 2 days in air and then heated in an oven at $70-80^{\circ} \mathrm{C}$ for another 2 days. Thereafter, the membrane was lifted from the Teflon plate and dried in a vacuum oven at $150^{\circ} \mathrm{C}$ for $20 \mathrm{~h}$. After this step, the temperature was raised to $200^{\circ} \mathrm{C}$ and the drying was continued for an additional $3 \mathrm{~h}$. The thickness of the membranes, calculated as an average of several thickness measurements, was in the range of $70-120 \mu \mathrm{m}$.

\section{RESULTS AND DISCUSSION}

Novel polymers with imide rings comprising diamine with flexible thioether and ether linkages, specifically, 4,4'-[oxybis(4,1-phenylenethio)]dianiline and four dianhydrides, were prepared by the conventional two-step procedure of ring-opening polyaddition in NMP and subsequent thermal cyclic dehydration without isolating the intermediate poly(amic acid). Two of the polymers are PIs, and another two contain amide linkages and are poly(amideimide)s. The chemical structures of the polymers synthesized in this work are presented in Figure 1.

\section{Polymer characterization}

The structure of the polymers was identified by FTIR spectroscopy. The typical FTIR spectra of the PIs are presented in Figure 2 for PI-III and PI-I.

In the FTIR spectra, the structure of the synthesized PIs was confirmed by the disappearance of the anhydride $\mathrm{C}=\mathrm{O}$ vibration bands at $\sim 1792$ and $1767 \mathrm{~cm}^{-1}$, and the appearance of the characteristic absorption of the imide ring at $1783-1776 \mathrm{~cm}^{-1}$ (asymmetric stretching vibration of a carbonyl) and at $1720-1723 \mathrm{~cm}^{-1}$ (symmetric stretching of carbonyl), as well as that of the C-N bond at

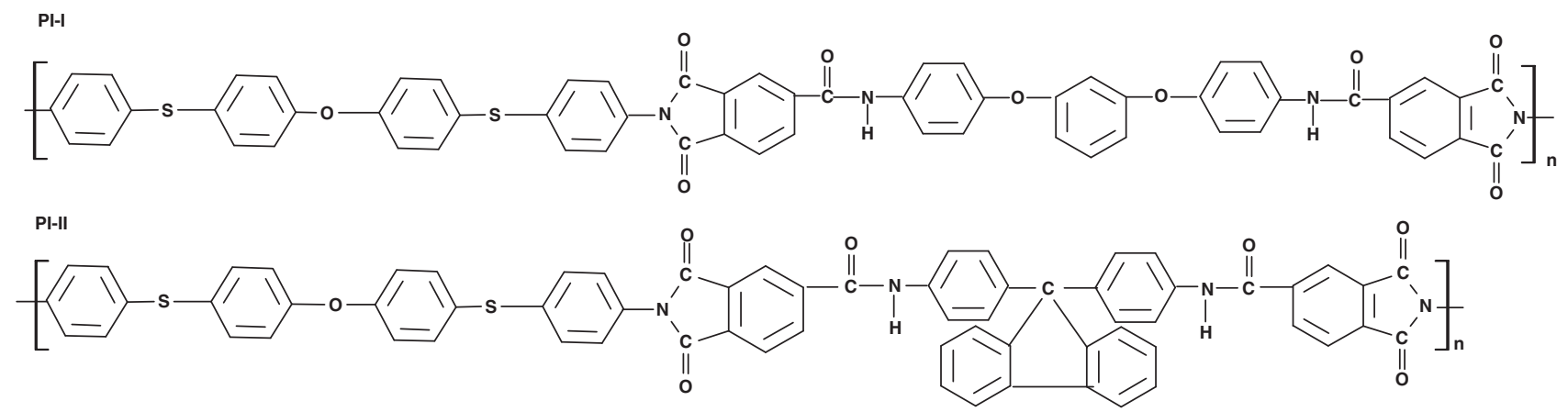<smiles></smiles><smiles>Cc1ccc(Sc2ccc(Oc3ccc(Sc4ccc(N5C(=O)c6ccc(C(F)(F)C(F)(F)F)cc6C5=O)cc4)cc3)cc2)cc1</smiles>

Figure 1 Chemical structures of the investigated polyimide (PI) polymers. 


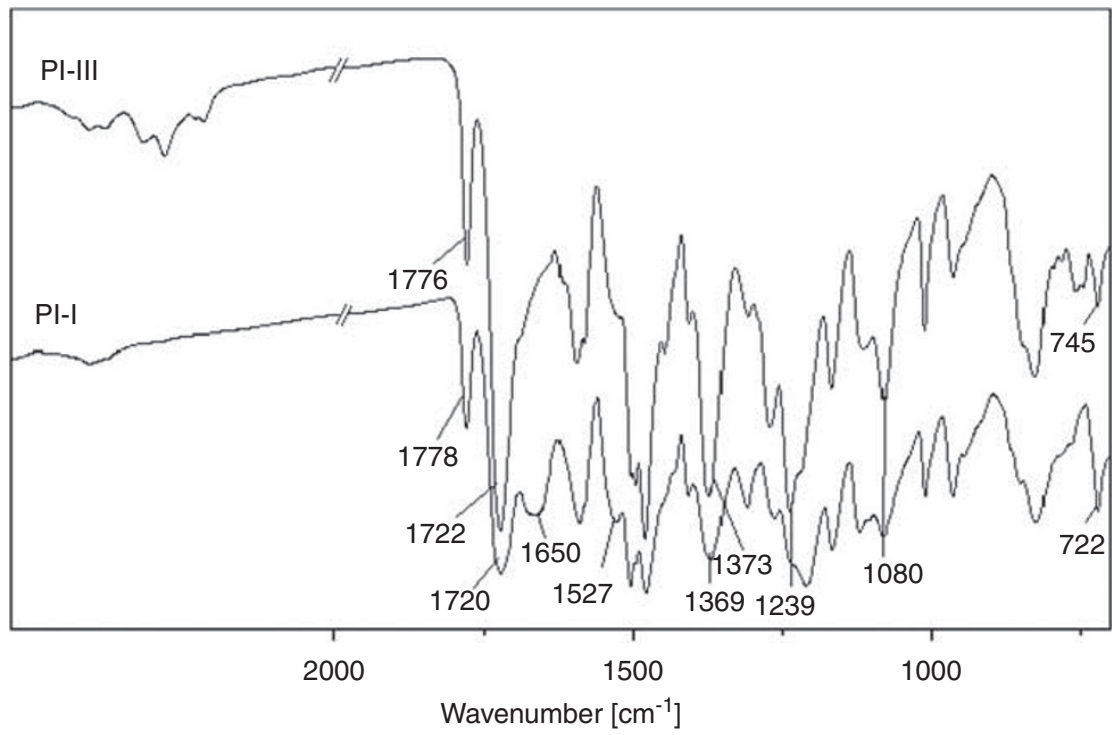

Figure 2 FTIR spectra of PI-I and PI-III. FTIR, Fourier-transform infrared; PI, polyimide.

Table 1 Physical properties of the obtained PIs

\begin{tabular}{|c|c|c|c|c|c|}
\hline \multirow[b]{2}{*}{ Polymer code } & \multirow[b]{2}{*}{$\rho\left(g m^{-3}\right)^{a}$} & \multirow[b]{2}{*}{ d-Spacing $(A ̊)$} & \multicolumn{3}{|c|}{ GPC datac } \\
\hline & & & $\mathrm{M}_{w}\left(\times 10^{4}\right)$ & $\mathrm{M}_{n}\left(\times 10^{4}\right)$ & $\mathrm{M}_{w} \mathrm{M}_{n}$ \\
\hline $\mathrm{PI}-\mathrm{I}$ & - & - & 1.184 & 0.6577 & 1.8 \\
\hline PI-II & 1.239 & 5.6 & 5.543 & 2.517 & 2.2 \\
\hline $\mathrm{PI}-\mathrm{III}$ & 1.210 & 5.12 & 8.782 & 3.813 & 2.3 \\
\hline PI-IV & 1.375 & 5.50 & 10.412 & 5.153 & 2.0 \\
\hline
\end{tabular}

Abbreviations: DMF, $\mathrm{N}, \mathrm{N}$-dimethylformamide; GPC, gel permeation chromatography; PI, polyimide. a Buoyancy method at $20^{\circ} \mathrm{C}$

'Calculated from WAXD data using Bragg's equation.

Relative to polystyrene standard, using DMF as the eluent.

$1369-1373 \mathrm{~cm}^{-1}$. In addition, absorption peaks at $740 \mathrm{~cm}^{-1}$, which are attributed to imide ring deformation, were detected. Moreover, the strong peak at $\sim 1239 \mathrm{~cm}^{-1}$ and at $\sim 1082 \mathrm{~cm}^{-1}$ due to the presence of ether linkages (Ar-O-Ar) ${ }^{4}$ and aromatic thioether linkages (Ar-SAr), ${ }^{22}$ respectively, were observed. The lack of amide groups in the case of PI-III and PI-IV (without amide linkages) was confirmed by proton nuclear magnetic resonance spectroscopy. No signal was observed in the range characteristic for amide protons, which indicates a virtually complete conversion of the poly(amic acid) precursor into PI. In the FTIR spectra of PI-I and PI-II, the absorption band at $1650 \mathrm{~cm}^{-1}$ originates from the vibration of amide linkages in the polymer backbone. In the spectrum of PI-IV, the hexafluoroisopropylidene (6F) group was identified by its absorption peak at $1210 \mathrm{~cm}^{-1}$. The elemental compositions of the PIs were checked by elemental analysis. The results of the elemental analyses show a good agreement with the calculated content of hydrogen and nitrogen in the proposed structures. However, a deficiency in carbon content of $1.30-3.63 \%$ was observed, and this is likely a result of the difficulties in burning these high-temperature polymers, which was also observed for other thermostable polymers. ${ }^{37}$ Thus, the obtained results for the synthesized polymers may be assumed to be in accordance with the proposed structures.

The molar masses of the polymers were measured with gel permeation chromatography, using polystyrene standards, and the data are presented in Table 1.
Table 2 Solubility behavior of the obtained PIs

\begin{tabular}{lccccccc}
\hline & \multicolumn{7}{c}{ Solvents } \\
\cline { 2 - 7 } Polymer code & $\mathrm{CHCl}_{3}$ & THF & DMF & NMP & DMSO & Cyclohexanone & $\mathrm{CH}_{3} \mathrm{CN}$ \\
\hline $\mathrm{PI}-\mathrm{I}$ & \pm & + & + & + & ++ & \pm & \pm \\
$\mathrm{PI}-\mathrm{II}$ & - & + & + & + & + & + & - \\
$\mathrm{PI}-\mathrm{III}$ & + & + & + & + & \pm & + & - \\
$\mathrm{PI}-\mathrm{IV}$ & + & + & + & + & + & + & - \\
\hline
\end{tabular}

Abbreviations: + , soluble at room temperature; \pm , partially soluble on heating; ++ , soluble on heating; - insoluble on heating; $\mathrm{CHCl}_{3}$, chloroform; $\mathrm{CH}_{3} \mathrm{CN}$ acetonitrile; DMF, $\mathrm{N}, \mathrm{N}$ dimethylformamide; DMSO, dimethylsulfoxide; NMP, $\mathrm{N}$-methyl-2-pyrrolidinone; $\mathrm{PI}$, polyimide; THF, tetrahydrofuran.

The qualitative solubility was tested with $2.5-\mathrm{mg}$ samples in $1 \mathrm{ml}$ of solvent.

The gel permeation chromatography measurements demonstrated that the polymers exhibited rather high values of molar masses, especially for PI-IV, with a low polydispersity in the range of 1.8-2.3.

The solubility of the synthesized PIs was qualitatively determined by the dissolution of $2.5 \mathrm{mg}$ of the solid in $1 \mathrm{ml}$ of organic solvent at room temperature and under heating. Table 2 lists the solubility of the PIs in different organic solvents.

All polymers were easily soluble in polar aprotic solvents, such as NMP and dimethylformamide, at room temperature. These PIs were soluble even in low-boiling-point solvents of the ether type, such as THF. The improved solubility of the presented polymers compared with that of traditional PIs can be explained by the presence of flexible ether and thioether bridges in the polymer chains together with groups that introduce a disruption in the chain linearity. The introduction of bulky isopropylidene, hexafluoroisopropylidene and fluorenylidene moieties in the polymer backbone increases the free volume of the polymers because of the looser chain packing and the decreased intermolecular interactions, which in turn enhances polymer solubility. The best solubility was exhibited by PI-IV, which contains hexafluoroisopropylidene units in the backbone. Both the PI-III and the PI-IV polymers were soluble even in chloroform.

The supramolecular structure of the obtained polymer powders was evaluated with wide-angle X-ray diffraction experiments. X-ray patterns obtained from these measurements are shown in Figure 3. 


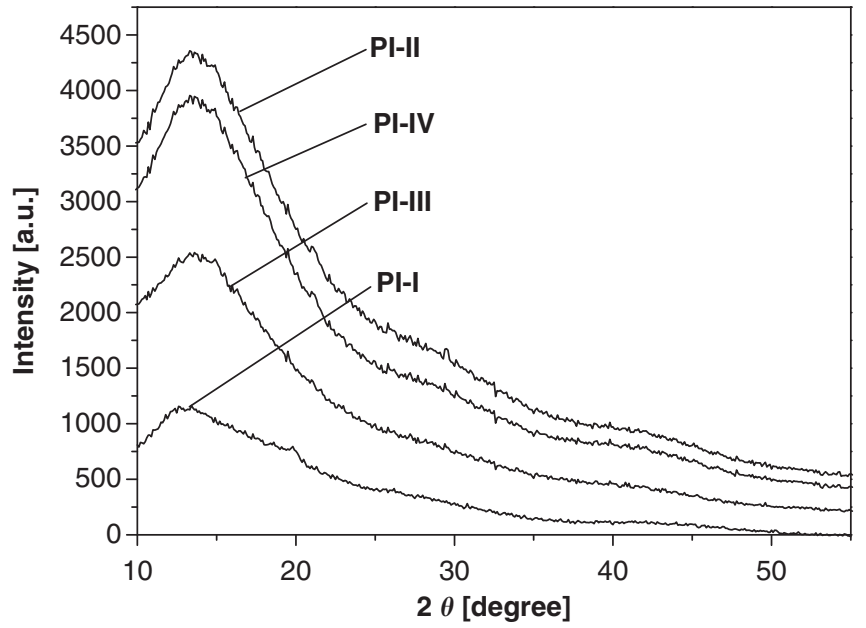

Figure 3 X-ray diffraction patterns of the prepared PIs. PI, polyimide.

Table 3 Thermal behavior data of PIs studied

\begin{tabular}{|c|c|c|c|c|c|c|}
\hline \multirow[b]{2}{*}{$\begin{array}{l}\text { Polymer } \\
\text { code }\end{array}$} & \multicolumn{3}{|c|}{$T G A$} & \multicolumn{3}{|l|}{$\mathrm{T}_{g}\left({ }^{\circ} \mathrm{C}\right)$} \\
\hline & $\mathrm{T}_{5 \%}\left({ }^{\circ} \mathrm{C}\right)$ & $\mathrm{T}_{\max }\left({ }^{\circ} \mathrm{C}\right)$ & $\begin{array}{c}\text { Char yield } \\
(\%)^{\mathrm{a}}\end{array}$ & $\begin{array}{c}\text { DSC } \\
\text { powder }\end{array}$ & $\begin{array}{l}\text { DSC } \\
\text { film }\end{array}$ & $D M A$ \\
\hline PI-I & 459 & 532 & 59 & 179 & - & - \\
\hline PI-II & 423 & 520 & 61 & 298 & 264 & 259 \\
\hline PI-III & 496 & 514 & 60 & 175 & 166 & 199 \\
\hline P-IV & 515 & 535 & 75 & 232 & 224 & 242 \\
\hline
\end{tabular}

Abbreviations: DMA, dynamic mechanical thermal analysis; DSC, differential scanning calorimetry; PI, polyimide; $T_{5} \%$, temperatures at $5 \%$ weight loss; $\mathrm{Tg}$, glass transition temperature; TGA, thermogravimetric analysis; $T_{\max }$, temperature of maximum decomposition rate. aResidual weight when heated to $600{ }^{\circ} \mathrm{C}$ in nitrogen.

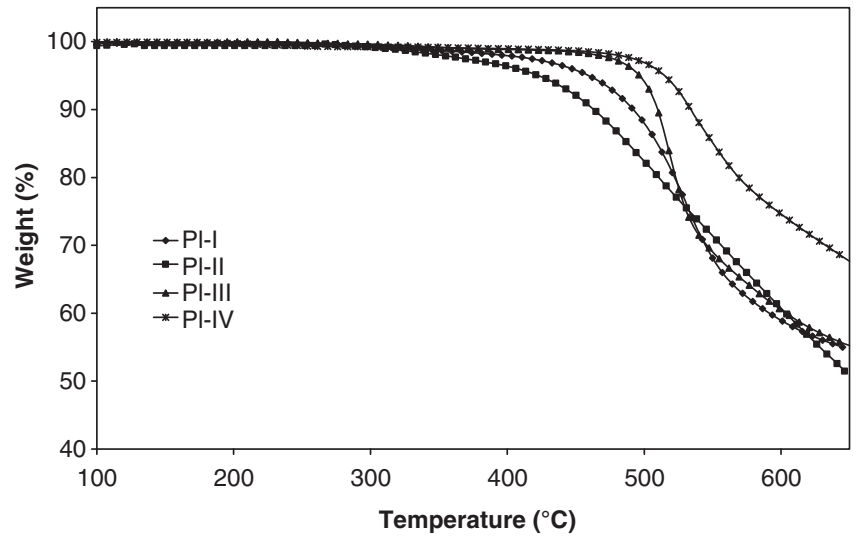

Figure 4 Thermogravimetric curves of the investigated PIs. PI, polyimide.

One broad diffraction peak of the diffusion type centered at $\sim 13^{\circ}$ (20) was observed for all studied samples (Figure 3). All polymers showed the same diffraction patterns that are typical for fully amorphous materials.

\section{Thermal properties}

The thermal decomposition and deformation behavior of the polymers was evaluated with TGA, DSC and DMA. The results are summarized in Table 3. The TGA curves of the polymers are shown in Figure 4.
All PIs exhibited similar TGA pattern characteristics for a one-step decomposition process. By taking into account the results from TGA analysis, it was found that the obtained PIs demonstrated good thermal stability without significant weight loss below $350^{\circ} \mathrm{C}$. This finding implies that no thermal decomposition occurred below this temperature and that the onset decomposition temperature was as high as $400{ }^{\circ} \mathrm{C}$. The $5 \%$ weight loss temperature $\left(T_{5}\right)$, which is usually considered the criterion for determining the thermal stability of high-temperature polymers, was in the range of $423-515{ }^{\circ} \mathrm{C}$. The temperature of the maximum decomposition rate $\left(T_{\max }\right)$, as evidenced by the differential thermogravimetric (DTG) curves, was in the range of $514-535^{\circ} \mathrm{C}$ (Table 3). Furthermore, the residual weight at $600{ }^{\circ} \mathrm{C}$ in nitrogen was in the range of $59-75 \%$. The char yield percent at $600{ }^{\circ} \mathrm{C}$ was the highest in the polymers containing hexafluoroisopropylidene $(6 \mathrm{~F})$ groups because of the presence of F atoms. $^{38}$

The $T_{\mathrm{g}}$ of the PI samples, which is one of the key parameters of polymers when considering high-temperature circumstances during fabrication and long-term heat-releasing environments, was determined by the DSC analysis. All studied PIs yield similar DSC profiles with no melting endotherms and a clear $T_{\mathrm{g}}$ transition. These findings clearly confirmed their amorphous nature. The DSC curves recorded with repeating heating-cooling cycles allowed the evaluation of the $T_{\mathrm{g}}$ values, which were found to be in the range of $175-298^{\circ} \mathrm{C}$ (Table 3). It is obvious that thermal properties depend on the polymer structure. By taking into account the polymer backbone microstructure, it was found that fluorenylidene diphenyl units in PI (PI-II) significantly increased the $T_{\mathrm{g}}$ value, and this polymer exhibited the highest $T_{\mathrm{g}}$. On the other hand, the introduction of isopropylidene moieties into the polymer chain decreased the $T_{\mathrm{g}}$ value (PI-III).

All polymers, except for PI-I, were formed as freestanding films, and DMA analysis was performed for those films. The temperature dependence of the dynamic storage modulus $\left(E^{\prime}\right)$, loss modulus $\left(E^{\prime \prime}\right)$ and $\tan \delta$ is shown in Figure 5 for PI-III as the exemplary polymer.

In DMA analysis, $T_{\mathrm{g}}$ can be defined in three ways: ${ }^{39}$ (i) the temperature at which $E^{\prime}$ has fallen to a certain value; (ii) the temperature at which $\tan \delta$ has its maximum value; and (iii) the temperature at which $E^{\prime \prime}$ has it maximum value. By taking into account the $T_{\mathrm{g}}$ values of the polymers evaluated from the loss modulus and $\tan \delta$, small differences were detected. The $T_{\mathrm{g}}$ values resulting from the $\tan \delta$ maximum are higher than those estimated from the maximum $E^{\prime \prime}$ by $6-11^{\circ} \mathrm{C}$ depending on the PI. The highest difference was detected in the case of PI-II $\left(11^{\circ} \mathrm{C}\right)$ and the smallest difference was detected for PI-IV $\left(6^{\circ} \mathrm{C}\right)$. The definition of the $T_{\mathrm{g}}$ as the temperature at which $\tan \delta$ attains its maximum value is common in the literature, ${ }^{39}$ and these values are gathered in Table 3 . The two different $T_{\mathrm{g}}$ evaluation methods applied in this study (DSC, DMA) provide different absolute values of $T_{\mathrm{g}}$ for a given polymer film. In the DMA measurements, the PIs PI-III and PI-IV show the higher $T_{\mathrm{g}}$, and PI-II possesses the lower one. Some differences can also be seen between the $T_{\mathrm{g}}$ values obtained for powder samples and the films using the DSC method (Table 3). This finding may be because of the plasticization effect caused by some residual solvent remaining in the films but not detected by the DSC analysis. On the other hand, the differences between the DSC and DMA data can be attributed to the different response of PIs to the evaluation system. ${ }^{40}$ The DMA measurements not only reveal the glass transition of polymers but also reflect their mechanical properties. ${ }^{28}$ The PIs studied show initial $\left(30^{\circ} \mathrm{C}\right)$ storage moduli $\left(E^{\prime}\right)$ of $150 \mathrm{MPa}$ for PI-II, $91 \mathrm{MPa}$ for PI-III and $89 \mathrm{MPa}$ for PI-IV. The PIs maintained their mechanical properties up to their $T_{\mathrm{g}}$ values, after which the $E^{\prime}$ values dropped rapidly. 


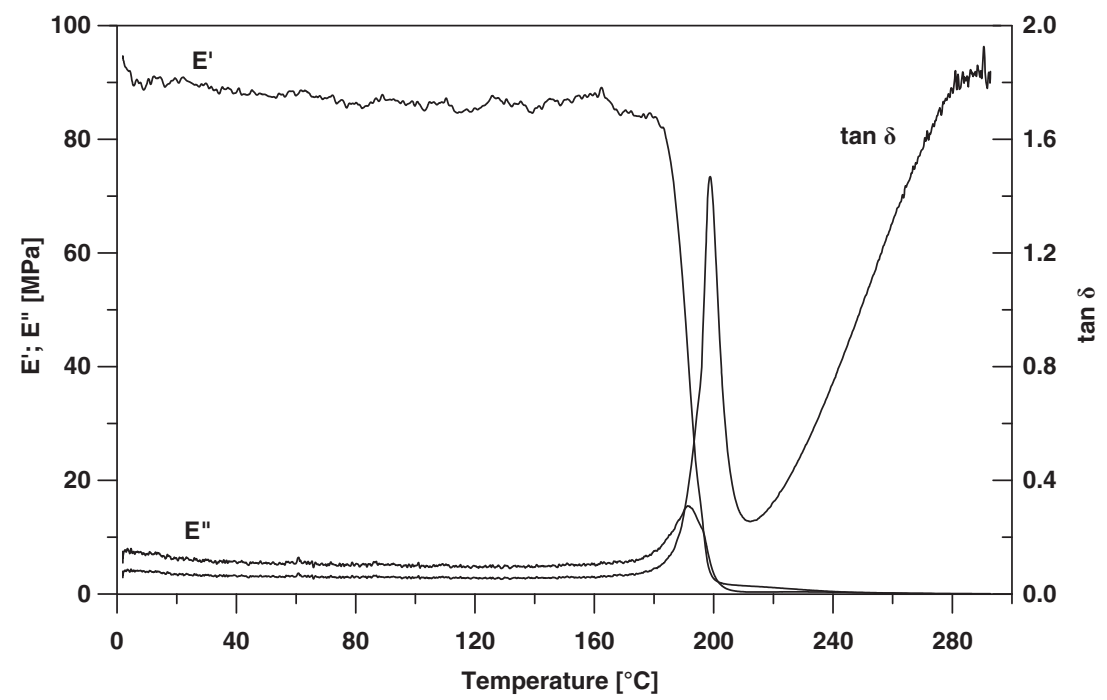

Figure 5 DMA curves of $\mathrm{PI}-\mathrm{III}\left(1 \mathrm{~Hz}, 3^{\circ} \mathrm{C}\right.$ per min). DMA, dynamic mechanical thermal analysis; PI, polyimide.

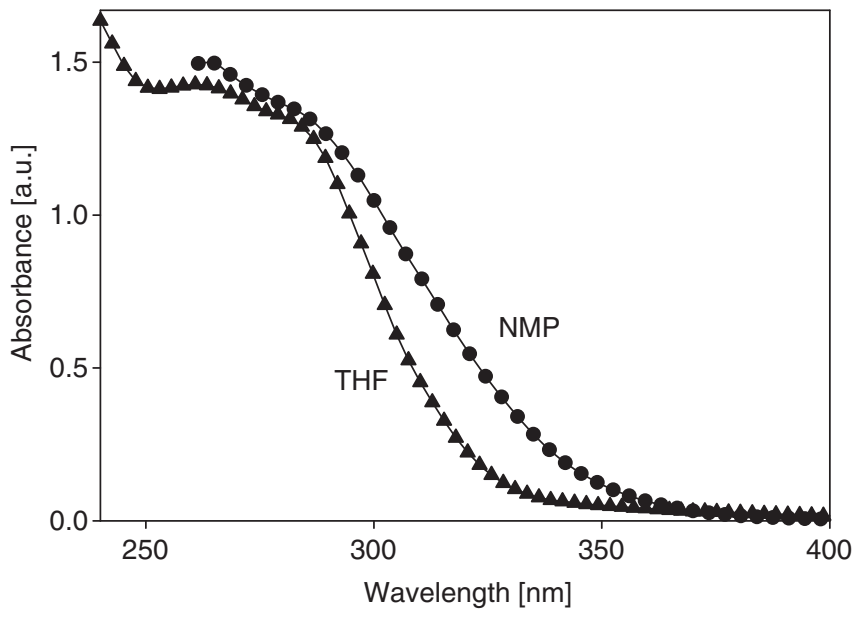

Figure 6 UV-Vis spectra of PI-IV in NMP and THF solutions. NMP, N-methyl2-pyrrolidinone; PI, polyimide; THF, tetrahydrofuran; UV-Vis, UV-visible.

\section{Optical properties}

The optical properties of the studied PIs were analyzed with UV-VisNIR (near-infrared) spectroscopy. The UV-Vis absorption spectra were recorded both in NMP and in THF solutions with a concentration of $10^{-5} \mathrm{moll}^{-1}$, suitable for the optical investigations, and in the solid state. The transmission $(T \%)$ and reflectivity $(R \%)$ spectra for the polymer films (freestanding films: PI-II, PI-III and PI-IV) and the thin film on the glass substrate (PI-I) were obtained in the wide range of $200-2500 \mathrm{~nm}$. The short wave range of the spectra was limited by the permeability of the used solvent (that is, $240 \mathrm{~nm}$ for THF and $260 \mathrm{~nm}$ for NMP) or by the glass substrate $(300 \mathrm{~nm})$.

The representative absorption spectra of PI-IV in the THF and NMP solutions are depicted in Figure 6, whereas the positions of the maximum absorption bands $\left(\lambda_{\max }\right)$ for all polymers in THF and NMP are gathered in Table 4.

The electronic spectra of the studied polymers exhibited similar characteristic with one absorption band due to $\pi-\pi^{*}$ transition in the polymer chain. The solvatochromic behavior in two solvents with different polarities, namely, NMP $(\varepsilon=33.0)$ and THF $(\varepsilon=7.58)$, was investigated. By taking into consideration the obtained results
Table 4 Optical properties and films thicknesses (d) of PIs

\begin{tabular}{|c|c|c|c|c|c|c|c|}
\hline \multirow{2}{*}{$\begin{array}{l}\text { Polymer } \\
\text { code }\end{array}$} & \multicolumn{2}{|c|}{$\lambda_{\max }(n m)$} & \multirow{2}{*}{$\begin{array}{l}\mathrm{T}_{450} \\
(\%)\end{array}$} & \multirow{2}{*}{$\begin{array}{l}\mathrm{T}^{\prime} 850 \\
(\%)\end{array}$} & \multirow[b]{2}{*}{$\mathrm{E}_{g}(\mathrm{eV})^{\mathrm{a}}$} & \multirow[b]{2}{*}{$\mathrm{n}$} & \multirow[b]{2}{*}{$\mathrm{d}(\mu \mathrm{m}}$, \\
\hline & $N M P$ & THF & & & & & \\
\hline PI-I & $268,308^{b}$ & $264^{b}, 289^{b}, 369^{b}$ & 83 & 94 & 2.70 & 1.94 & $2.5^{\mathrm{c}}$ \\
\hline PI-II & $274,309^{b}$ & $274^{b}, 309^{b}$ & 67 & 85 & 2.77 & 1.50 & 11 \\
\hline $\mathrm{PI}-\mathrm{III}$ & $269,290^{b}$ & $241,262^{b}, 291^{b}$ & 58 & 84 & 2.97 & 1.96 & 17 \\
\hline P-IV & $263,288^{b}$ & $261,288^{b}$ & 54 & 89 & 2.89 & 1.64 & 26 \\
\hline
\end{tabular}

Abbreviations: NMP, $N$-methyl-2-pyrrolidinone; $\mathrm{PI}$, polyimide; $\mathrm{T}_{450}$, transmittance at $450 \mathrm{~nm}$; $\mathrm{T}^{\prime} 850$, transmittance at $850 \mathrm{~nm}$; THF, tetrahydrofuran.

aptical energy gap.

bThe position of absorption band calculated using the second derivatives method (that is, the minimum of the second derivative of absorption corresponds to the absorption maximum). cFilm on glass.

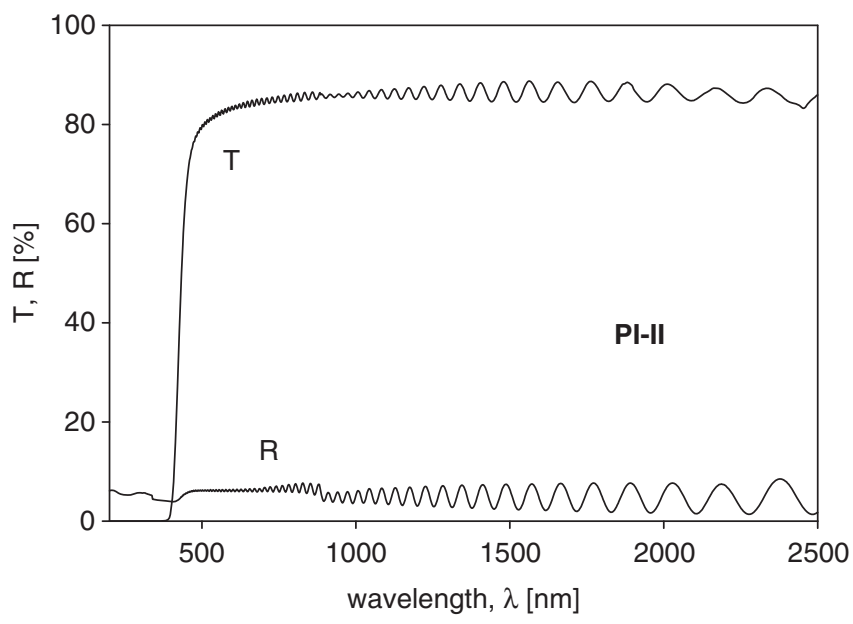

Figure 7 UV-Vis-NIR spectra of PI-II (film thickness: $\sim 10 \mu \mathrm{m}$ ). PI, polyimide; $\mathrm{R}$, reflectivity; T, transmission; UV-Vis-NIR, UV-visible-near infrared.

that are demonstrated in Figure 7 and Table 4, it can be noted that the spectra show a $\lambda_{\max }$ position at almost the same wavelength despite the different polarities of the solvents. However, in some cases, the absorption band recorded in the NMP solution is broadened 


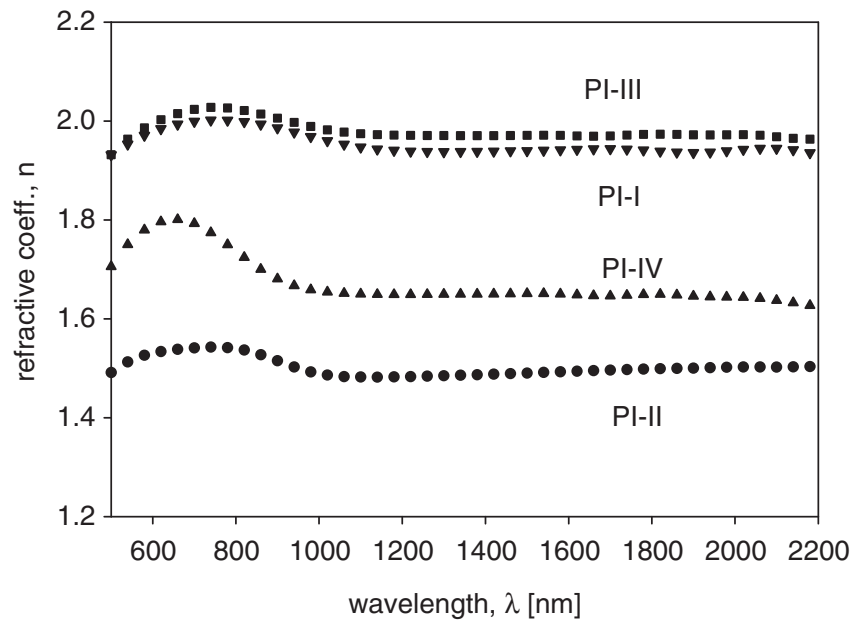

Figure 8 Spectral dependence of the refractive index for the investigated PIs. PI, polyimide.

toward the lower energy region in comparison with that recorded in THF (Figure 6).

Figure 7 displays typical UV-Vis-NIR transmission (T) and reflectivity (R) spectra of the PI-II freestanding film with a thickness of $\sim 10 \mu \mathrm{m}$.

All investigated freestanding films (PI-II, PI-III and PI-IV) and the thin film on the glass substrate (PI-I) were transparent and yellow with transmission levels $>50 \%$ at $450 \mathrm{~nm}$. In the spectral range $>850 \mathrm{~nm}$ (low energy range), the transmission is almost constant at $84-89 \%$ (Figure 7 and Table 4 ) and the reflectivity is on the level of $3-7 \%$. This finding means that these studied PIs exhibited similar optical permeabilities.

The Kramers-Kronig analysis ${ }^{41}$ applied to the reflectivity spectra of the investigated films yields the values of the refractive index $(n)$ in the low-energy region, as shown in Figure 8.

The largest $n$ values, $>1.9$, were found for polymers PI-I and PI-II.

Further, knowing $n$, the film thickness $(d)$ could be determined from the interferences (seen in both $\mathrm{T}$ and $\mathrm{R}$ spectra) in a manner similar to interference spectroscopy. ${ }^{42}$

The absorption coefficient $(\alpha)$ of these polymer films was calculated from the transmission and reflectivity measurements according to formulae given in Manifacier et al. ${ }^{43}$ and the calculations are visualized in Figure 9a.

The absorption edges of all investigated films have been found to follow the Tauc power law $\alpha \propto\left(E-E_{\mathrm{G}}\right)^{2}$, which is typical for amorphous semiconductors. Thus, the energy gaps $\left(E_{G}\right)$ of the films were deduced from the linear approximation of the $(\alpha E)^{1 / 2}=f(E)$ dependence, as presented in Figure 9b. This approach, typical for amorphous semiconductors, has also been applied to obtain the energy gaps of both amorphous freestanding polymer films ${ }^{44-46}$ and thin films on glass. ${ }^{47-48}$ The smallest values of the energy gap were found for polymers PI-I and PI-II, which indicates better conjugation in these PIs. The conjugation region in PI-I and PI-II is slightly higher than that in the other studied PIs (PI-III and PI-IV) because of the presence of a carbonyl group connected with aromatic imide rings.

\section{Gas transport properties}

The gas permeability coefficients $(P)$ and the ideal selectivity values $(\alpha)$ of the PIs synthesized in this work measured for different gases at $30^{\circ} \mathrm{C}$ and $6 \mathrm{~atm}$ are summarized in Table 5 .
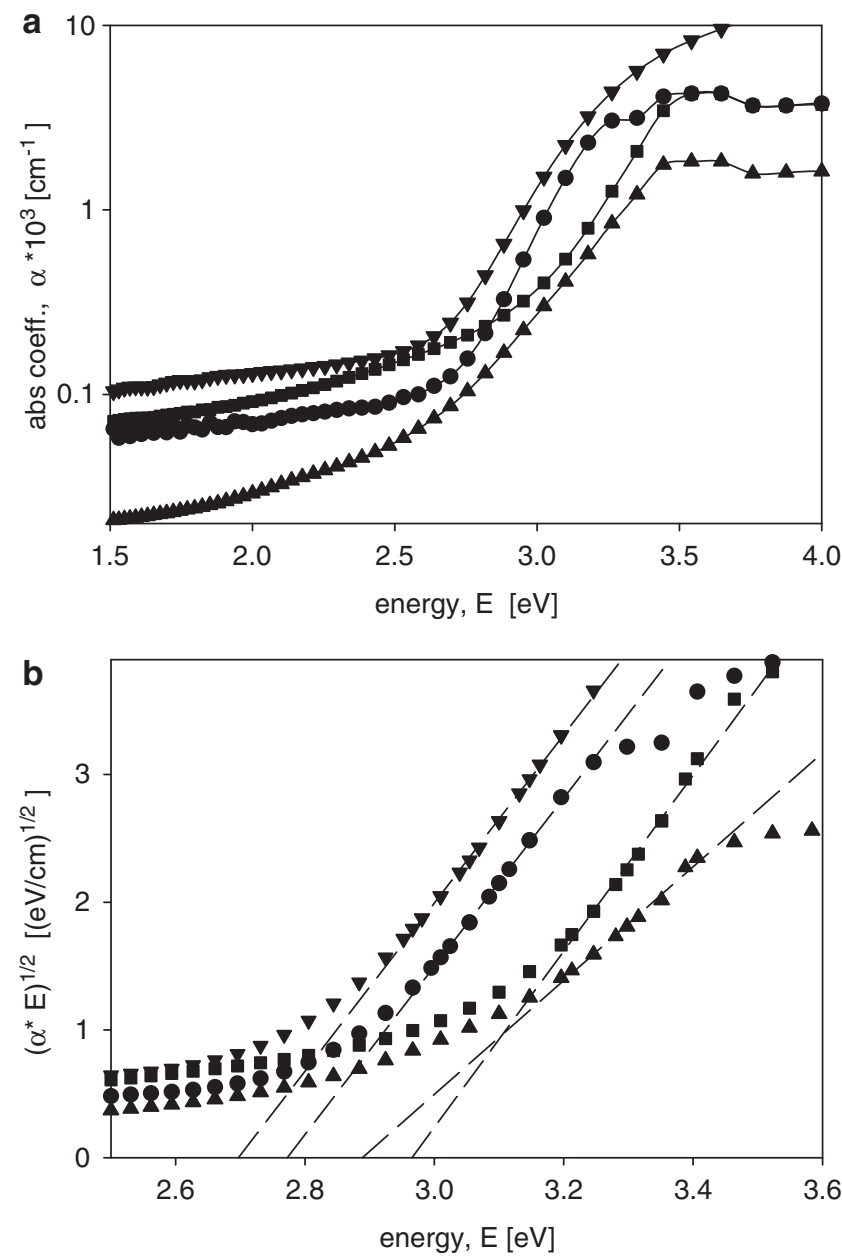

Figure 9 Absorption coefficient (a) and the Tauc relation (b) used to obtain the energy gaps.

Table 5 Gas transport properties of the PI-based membranes at 6 atm and at $30^{\circ} \mathrm{C}$

\begin{tabular}{|c|c|c|c|c|c|c|}
\hline \multirow[b]{2}{*}{ Polymer code } & \multicolumn{4}{|c|}{ Permeability P (Barrer) } & \multicolumn{2}{|c|}{ Ideal selectivity $\alpha$} \\
\hline & $\mathrm{He}$ & $\mathrm{O}_{2}$ & $\mathrm{~N}_{2}$ & $\mathrm{CO}_{2}$ & $\mathrm{O}_{2} / \mathrm{N}_{2}$ & $\mathrm{CO}_{2} / \mathrm{N}_{2}$ \\
\hline PI-III & 3.56 & 0.231 & 0.041 & 0.686 & 5.6 & 16.7 \\
\hline PI-IV & 12.21 & 1.12 & 0.138 & 1.58 & 8.1 & 11.5 \\
\hline PI-lit ${ }^{a}$ & 18.3 & 1.73 & 0.313 & 7.85 & 5.5 & 25.0 \\
\hline
\end{tabular}

Abbreviation: PI, polyimide.

aData from Hirayama et al., ${ }^{54}$ tested at $1.5 \mathrm{~atm}$ and $35^{\circ} \mathrm{C}$

In this study, the permeability measurements for PI-I membrane could not be recorded because of the brittleness of the membrane. In the case of PI-II, the gas permeation rate through the membrane was too low to obtain reliable permeability data under the experimental conditions applied. In Table 5, the data received for PI-III and PI-IV show that the permeability of both polymers decreases in the following order of the gases:

$$
\mathrm{He}>\mathrm{CO}_{2}>\mathrm{O}_{2}>\mathrm{N}_{2}
$$

This finding is in the order of increasing gas molecule size, as shown by the respective kinetic diameter values ${ }^{49}$ given in Table 6 . 
Table 6 Kinetic diameters and critical temperatures of the gases tested

\begin{tabular}{|c|c|c|}
\hline Gas & Kinetic diameter $(A)^{\mathrm{a}}$ & Critical temperature $\mathrm{T}_{c}(K)^{\mathrm{b}}$ \\
\hline Helium & 2.60 & 5.26 \\
\hline Oxygen & 3.46 & 154.4 \\
\hline Nitrogen & 3.64 & 126.2 \\
\hline Carbon dioxide & 3.30 & 304.2 \\
\hline
\end{tabular}

aData from Breck. ${ }^{49}$

bData from Braker and Le Mossman. ${ }^{50}$

Moreover, the gas condensability expressed by the respective critical temperature values ${ }^{50}$ listed in Table 6 decreases in the same order from $\mathrm{CO}_{2}$ to $\mathrm{N}_{2}$. This result is in accordance with the literature, ${ }^{51}$ which states that smaller and easily condensable gases permeate faster than bigger and less condensable ones.

As can be seen from the data given in Table 5, the permeability of the PIs studied is rather low, similar to that of many PIs reported in the literature. ${ }^{52}$ However, the differences in the chemical structure of the dianhydride monomer strongly influence the gas permeation properties of the PI-based membranes for all gases studied. Hexafluoroisopropylidene moieties in the polymer chain, compared with the isopropylidiene ones, increase the PI permeability by a factor of 3.4 for both $\mathrm{He}$ and $\mathrm{N}_{2}$ and by a factor of 4.9 for $\mathrm{O}_{2}$, whereas the $\mathrm{CO}_{2}$ permeability was found to increase 2.3 times for PI-IV. In accordance with the trade-off observed between the permeability and selectivity for most polymers, ${ }^{53}$ the enhanced permeability of PI-IV is accompanied by its lower selectivity toward $\mathrm{CO}_{2} / \mathrm{N}_{2}$ gas pairs. For comparison, Table 5 shows the permeability and selectivity data found in the literature for PI obtained from the same 4,4'-(hexafluoroisopropylidene)diphthalic anhydride and 4,4'-[oxybis(p-phenyleneoxy)] aniline with only ether linkages between phenyl rings. ${ }^{54}$ The reported permeability data for this polymer are five times higher for $\mathrm{CO}_{2}$ and slightly higher for the other gases. By taking into account the fact that these data were obtained at higher temperatures and at much lower feed pressures than those used in this study, the observed differences are probably less significant except for $\mathrm{CO}_{2}$. However, because the pressure dependence of $\mathrm{CO}_{2}$ permeability is more severe than that for other gases, the true value of $P\left(\mathrm{CO}_{2}\right)$ for PI-IV that is uncomplicated by this effect may be much closer to the value reported in the literature.

In Tables 1 and 3, some physical properties of the synthesized PIs, which may be related to their gas transport properties, are presented. For comparison, the relevant literature data for PI-lit are as follows: $\rho=1.389 \mathrm{~g} \mathrm{~cm}^{-3} ; d$-spacing $=5.53 \AA ; T_{\mathrm{g}}=251{ }^{\circ} \mathrm{C}\left(10^{\circ} \mathrm{C}\right.$ per min $)$. The PIs from hexafluoroisopropylidene-based dianhydride, PI-IV and PIlit, have similar densities, which are higher than that of PI-III because of the presence of fluorine atoms. By comparing the $T_{\mathrm{g}}$ values of PI-III and PI-IV, it can be seen that the bulky $\mathrm{CF}_{3}$ groups hinder the rotation of the polymer chain segments, thus decreasing the chain flexibility, as demonstrated by the higher $T_{\mathrm{g}}$ value of PI-IV (Table 3 ). Gas diffusivity is generally expected to be enhanced by the increased polymer chain flexibility. However, the flexibility may have a smaller contribution over the diffusion than the other polymer properties. It seems that the interchain spacing is more relevant in this case. As can be seen from the mean $d$-spacing values summarized in Table 1 , the higher interchain distance measured for PI-IV correlates with the fact that its permeability is greater than that of PI-III. Moreover, the similar permeabilities of PI-IV and PI-lit agree well with their similar $d$-spacing values. These high $d$-spacing values are attributed to the presence of bulky trifluromethyl groups, which disrupt chain packing and make the molecular structure more open. This, in turn, favors both gas sorption and diffusion.

\section{Conclusions}

4,4'-[Oxybis(4,1-phenylenethio)]dianiline-based PIs were synthesized using various aromatic dianhydrides. Most polymers were easily soluble in aprotic polar solvents and in THF, and they exhibited remarkable film-forming abilities. The obtained PIs showed high thermal stability, which renders advantages in various applications. Moreover, there is a large interval between $T_{\mathrm{g}}$ and the decomposition temperature of each polymer, which also could be advantageous in the processing of these polymers by the thermoforming technique. Two of the studied PIs exhibited relatively high refractive indices of $\sim 1.9$. The introduction of isopropylidene units into a polymer chain and the increase of the number of aromatic rings with ether linkages resulted in increasing indices of refraction for the PIs. The highest gas permeability was found for hexafluoroisopropylidene-based PI. This finding is in accordance with the high mean $d$-spacing value of this polymer, which results from the more open molecule structure created by the bulky $-\mathrm{CF}_{3}$ groups. The gas permeation properties as well as physical properties, except the $T_{\mathrm{g}}$ value, determined for this PI were found to be quite similar to those reported for PI obtained from the same dianhydride monomer and 4,4'-[oxybis(4,1-phenylenethio)]dianiline. This finding may suggest that the presence of the thioether linkages in the PI backbone in place of the ether linkages does not affect the polymer gas transport properties significantly.

Some polymers described in this article can be considered new candidates for high refractive index, processable, thermally stable polymeric materials.

\section{ACKNOWLEDGEMENTS}

This work was financed by Grant no N N209 086138 given by the Ministry of Science and Higher Education of Poland from its means for scientific research for the years of 2010-2012. We thank Mr M. Domański for the WAXD measurements, Professor A. Valozhin for the 4,4'-[oxybis(4,1-phenylenethio)] dianiline and Dr $\mathrm{H}$. Janeczek for the DSC characterization.

1 Sroog, C. E. Polyimides. J. Polym. Sci. Macromol. Rev. 11, 161-208 (1976).

2 Ghosh, M. K. \& Mittal, K. L. Polyimides: Fundamentals and Applications 7-48 (Marcel Dekker, New York, 1996).

3 Sazanov, Y. N. Applied significance of polyimides. Russian J. Appl. Chem. 74, 1253-1259 (2001).

4 Bruma, M., Damaceanu, M. D. \& Muller, P. Comparative study of polyimides containing oxadiazole and ether groups. High Perform. Polym. 21, 522-534 (2009).

5 Damaceanu, M. D., Rusu, R.- D., Bruma, M. \& Jarzabek, B. Photo-optical properties of poly(oxadiazole-imide)s containing naphthalene rings. Polym. J. 42, 663-669 (2010).

6 Pron, A., Gawrys, P. Zagórska, M., Djurado, D. \& Demadrille, R. Electroactive materials for organic electronics: preparation strategies, structural aspects and characterization techniques. Chem. Soc. Rev. 39, 2577-2632 (2010).

7 Gawrys, P., Djurado, D., Rimarcik, J., Kornet, A., Boudinet, D., Verilhac, J- M., Lukes, V., Wielgus, I., Zagorska, M. \& Pron, A. Effect of N-substituents on redox, optical, and electronic properties of naphthalene bisimides used for field-effect transistors fabrication. J. Phys. Chem. B 114, 1803-1809 (2010).

8 Gawrys, P., Boudinet, D., Zagorska, M., Djurado, D., Verilhac, J- M., Horowitz, G., Pecaud, J., Pouget, S. \& Pron, A. Solution processible naphthalene and perylene bisimides: synthesis, electrochemical characterization and application to organic field effect transistors (OFETs) fabrication. Synth. Met. 159, 1478-1485 (2009).

9 Wicklein, A., Lang, A., Muth, M. \& Thelakkat, M. Swallow-tail substituted liquid crystalline perylene bisimides: synthesis and thermotropic properties. J. Am. Chem. Soc. 131, 14442-14453 (2009).

10 Wang, Y., Zhang, X. X., Han, B., Peng, J., Hou, Sh., Huang, Y., Sun, H., Xie, M. \& $\mathrm{Lu}, \mathrm{Zh}$. The synthesis and photoluminescence characteristics of novel blue lightemitting naphthalimide derivatives. Dyes Pigm. 86, 190-196 (2010).

11 Jiang, W., Tang, J., Qi, Q., Wu, W., Sun, Y. \& Fu, D. The synthesis, crystal structure and photophysical properties of three novel naphthalimide dyes. Dyes Pigm. 80, 11-16 (2009). 
12 Yuan, Zh., Li, J., Xiao, Y., Li, Zh. \& Qian, X. Core-perfluoroalkylated perylene diimides and naphthalene diimides: versatile synthesis, solubility, electrochemistry, and optical properties. J. Org. Chem. 75, 3007-3016 (2010).

13 Wang, Y., Xu, Sh., Chen, T., Guo, H., Liu, Q., Ye, B., Zhang, Zh., He, Zh. \& Cao, Sh. Synthesis and preliminary photovoltaic behavior study of a soluble polyimide containing ruthenium complexes. Polym. Chem. 1, 1048-1055 (2010).

14 Woodhouse, M., Perkins, C. L., Rawls, M. T., Cormier, R. A., Liang, Z., Nardes, A. M. \& Gregg, B. A. Non-conjugated polymers for organic photovoltaics: physical and optohyphen-qj;electronic properties of Poly(perylene diimides). J. Phys. Chem. C. 114, 6784-6790 (2010).

15 An, Z., Yu, J., Domercq, B., Jones, S. C., Barlow, S., Kippelen, B. \& Marder, S. R. Room-temperature discotic liquid-crystalline coronene diimides exhibiting high chargecarrier mobility in air. J. Mater. Chem. 19, 6688-6698 (2009).

16 Siwy, M., Jarząbek, B., Świtkowski, K., Pura, B. \& Schab-Balcerzak, E. Novel poly (esterimide)s containing a push-pull type azobenzene moiety-synthesis, characterization and optical properties. Polym. J. 40, 813-824 (2008).

17 Schab-Balcerzak, E., Siwy, M., Kawalec, M., Sobolewska, A., Chamera, A. \& Miniewicz, A. Synthesis, characterization, and study of photoinduced optical anisotropy in polyimides containing side azobenzene units. J. Phys. Chem. A. 113, 8765-8780 (2009).

18 Glatz, F. P. \& Mulhaupt, R. Syntheses and properties of soluble poly(arylene thioether imide)s and the corresponding poly(arylene sulfone imide)s. Polym. Bull. 31, 137-143 (1993).

19 Xu, Z.- K., Bohning, M., Schultze, J. D., Li, G.- T., Springer, J., Glatz, F. P. \& Mulhaupt, R. Gas transport properties of poly(phenylene thioether imide)s. Polymer 38, 1573-1580 (1997).

20 Liu, J. G., Nakamura, Y., Shibasaki, Y., Ando, S. \& Ueda, M. Synthesis and characterization of highly refractive polyimides from $4,4^{\prime}$-thiobis[( $p$-phenylenesulfanyl)aniline] and various aromatic tetracarboxylic dianhydrides. J. Polym. Sci. A Polym. Chem. 45, 5606-5617 (2007)

21 Liu, J. G., Nakamura, Y., Ogura, T., Shibasaki, Y., Ando, S. \& Ueda, M. Optically transparent sulphur-containing polyamide- $\mathrm{Ti}_{2}$ nanocomposite films with high refractive index and negative pattern formation from poly(amic acid)- $\mathrm{TiO}_{2}$ nanocomposite film. Chem. Mater. 20, 273-281 (2008).

22 Liu, J. G., Nakamura, Y., Shibasaki, Y., Ando, S. \& Ueda, M. High refractive index polyimides derived from 2,7-bis(4-aminophenylenesulfanyl)thianthrene and aromatic dianhydrides. Macromolecules 40, 4614-4620 (2007).

23 Jiang, W., Wang, D., Guan, Sh., Gao, H., Zhao, Y., Jiang, Z., Gao, W., Zhang, D. \& Zhang, D. Sul-containing fluorinated polyimides for optical waveguide device. J. Photochem. Photobiol. A Chem. 197, 426-433 (2008).

24 You, N.- H., Suzuki, Y., Yorifuji, D., Ando, S. \& Ueda, M. Synthesis of high refractive index polyimides derived from 1,6-Bis( $p$-aminophenylsulfanyl)-3,4,8,9-tetrahydro2,5,7,10-tetrathiaanthracene and aromatic dianhydrides. Macromolecules 41, 6361-6366 (2008).

25 Fukuzaki, N., Higashihara, T., Ando, S. \& Ueda, M. Synthesis and characterization of highly refractive polyimides derived from thiophene-containing aromatic diamines and aromatic dianhydrides. Macromolecules 43, 1836-1843 (2010).

$26 \mathrm{Li}, \mathrm{Z}$., Liu, J. G. \& Yang, S.- Y. Synthesis and characterization of thioether and pyridinebridged aromatic polyimides with high refractive indices and high glass transition temperatures. High Perform. Polym. 22, 468-482 (2010).

27 Suzuki, Y., Liu, J. G., Nakamura, Y., Shibasaki, Y., Ando, S. \& Ueda, M. Synthesis of highly refractive and transparent polyimides derived from $4,4^{\prime}$-[ $p$-sulfonylbis(phenylenesulfanyl)]diphthalic anhydride and various sulphur-containing aromatic diamines. Polym. J. 40, 414-420 (2008).

28 Liu, J. G., Nakamura, Y., Terraza, C. A., Shibasaki, Y., Ando, S. \& Ueda, M. Highly refractive polyimides derived from 2,8-Bis( $p$-aminophenylenesulfanyl)dibenzothiophene and aromatic dianhydrides. Macromol. Chem. Phys. 209, 195-203 (2008).

29 Liu, J. G., Nakamura, Y., Shibasaki, Y., Ando, S. \& Ueda, M. High refractive index polyimides derived from 2,7-bis(4-aminophenylenesulfanyl)thianthrene and aromatic dianhydrides. Macromolecules 40, 4614-4620 (2009).

30 You, N.- H., Chueh, Ch.-Ch., Liu, Ch.-L., Ueda, M. \& Chen, W.-Ch. Synthesis and memory device characteristics of new sulphur donor containing polyimides. Macromolecules 42, 4456-4463 (2009).
31 Xiao, Y., Low, B. T., Hosseini, S. S., Chung, T. S. \& Paul, D. R The strategies of molecular architecture and modification of polyimide-based membranes for $\mathrm{CO}_{2}$ removal from natural gas-a review. Prog. Polym. Sci. 34, 561-580 (2009).

32 Bai, Z., Durstock, M. F. \& Dang, T. D. Proton conductivity and properties of sulfonated polyarylenethioether sulfones as proton exchange membranes in fuel cells. J. Memb. Sci. 281, 508-516 (2006).

33 Rubira, A. F., Rancourt, J. D., Caplan, M. L., St. Clair, A. K. \& Taylor, L. T. Optically reflective polyimide films created by in situ silver metal formation. Chem. Mater. 6, 2351-2358 (1994).

34 Sêk, D., Schab-Balcerzak, E. \& Grabiec, E. New semiladder polymers. Part II: synthesis and properties of new poly(amideimidazopyrrolones). Polymer 40, 2419-2428 (1999).

35 Sêk, D., Grabiec, E., Sobolewska, A. \& Miniewicz, A. Influence of new polymers structures on their optical properties. e-Polymers 71, (2004).

36 Schab-Balcerzak, E., Grabiec, E., Jarząbek, B., Grobelny, Ł., Kurcok, M. \& Mazurak, Z. Novel soluble aromatic poly(amideimide)s containing 9,9-diphenylfluorene moieties: characterization and optical properties. Cent. Eur. J. Chem. 4, 604-619 (2006).

37 Yang, Ch.-J. \& Jenekhe, S. A. Conjugated aromatic polyimines. 2. synthesis, structure, and properties of new aromatic polyazomethines. Macromolecules 28, 1180-1196 (1995).

38 Simpson, J. O. \& St.Clair, A. K. Fundamental insight on developing low dielectric constant polyimides. Thin Solid Films 308-309, 480-485 (1997).

39 Wang, X. L., Gong, Y. F., Ma, T. \& Yang, F. C. Synthesis and properties of new pyridinebridged poly(ether-imide)s based on 4-(4-trifluoromethylphenyl)-2,6-bis[4-(4-aminophenoxy) phenyl]pyridine. J. Fluor. Chem. 129, 56-63 (2008).

40 Rieger, J. The glass transition temperature $T_{\mathrm{g}}$ of polymers-comparison of the values from differential thermal analysis (DTA, DSC) and dynamic mechanical measurements (torsion pendulum). Polym. Test. 20, 199-204 (2001).

41 Liu, J. G., Nakamura, Y., Shibasaki, Y., Ando, S. \& Ueda, M. Synthesis and characterization of high refractive index polyimides derived from 4,4'-( $p$-phenylenedisulfanyl)dianiline and various aromatic tetracarboxylic dianhydrides. Polym. J. 39, 543-550 (2007).

42 Fellman, J. \& Westerlund, T. Determination of the complex indices of refraction of glasses using Kramers-Krönig transformation. J. Non-Cryst. Solids 146, 165-174 (1992).

43 Manifacier, J. C., Gasiot, J. \& Fillard, J. P. A simple method for the determination of the optical constants $\mathrm{n}, \mathrm{k}$ and the thickness of a weakly absorbing thin film. J. Phys. E Sci. Instrum. 9, 1002 (1976).

44 Jarzabek, B., Weszka, J., Burian, A. \& Pocztowski, G. Optical properties of amorphous thin films of the Zn-P system. Thin Solid Films 279, 204-208 (1996).

45 Jarzabek, B., Orlik, T, Cisowski, J, Schab-Balcerzak, E. \& Sek, D. Optical properties of semiladder polymer films. Acta. Phys. Pol. A 98, 655-659 (2000).

46 Jarzabek, B., Schab-Balcerzak, E., Chamenko, T., Sek, D., Cisowski, J. \& Volozhin, A. Optical properties of new aliphatic-aromatic co-polyimides. J. Non-Cryst. Solids 299, 1057-1061 (2002).

47 Jarzabek, B., Weszka, J., Domański, M., Jurusik, J. \& Cisowski, J. Optical properties of amorphous polyazomethine thin films. J. Non-Cryst. Solids 352, 1660-1662 (2006).

48 Jarzabek, B., Weszka, J., Domański, M., Jurusik, J. \& Cisowski, J. Optical studies of aromatic polyazomethine thin films. J. Non-Cryst. Solids 354, 856-862 (2008).

49 Breck, D. Zeolite Molecular Sieves (Wiley, NY, 1994).

50 Braker, W. \& Le Mossman, A. Matheson Gas Data Book (McGraw Hill, NY, 1971).

51 Crank, J. \& Park, G. S. Diffusion in Polymers (AP Incorp. (London) LTD, London, 1968).

52 Powell, C. E. \& Qiao, G. G. Polymeric $\mathrm{CO}_{2} / \mathrm{N}_{2}$ gas separation membranes for the capture of carbon dioxide from power plant flue gases. J. Membr. Sci. 279, 1-49 (2006).

53 Robeson, L. M. The upper bound revisited. J. Membr. Sci. 320, 390-400 (2008).

54 Hirayama, Y., Yoshinaga, T., Kusuki, Y., Ninomiya, K., Sakakibara, T. \& Tamari, T. Relation of gas permeability with structure of aromatic polyimides I. J. Membr. Sci. $111,169-182$ (1996). 